\title{
OS PROJETOS DE TRABALHO SEGUNDO HERNÁNDEZ (1998) E SUAS CONTRIBUIÇÕES PARA A PRÁTICA PEDAGÓGICA DO PROFESSOR DE PRÉ-ESCOLA
}

\author{
Indira Aparecida Santana Aragão Favareto \\ Universidade Estadual Paulista - UNESP, Programa de Pós-Graduação em Educação, Presidente Prudente, SP.
}

\section{RESUMO}

O presente artigo caracteriza-se como um recorte da pesquisa de mestrado que se encontra em andamento no Programa de Pós Graduação em Educação-PPGE da Faculdade de Ciências e Tecnologia -FCT- Unesp de Presidente Prudente. O objetivo da pesquisa se constitui buscar identificar e refletir as contribuições dos projetos de trabalho segundo Hernández (1998) para a prática pedagógica do professor de pré-escola. Para atingir os objetivos propostos a pesquisa se respaldou nos princípios da pesquisa qualitativa, e utilizou-se da análise documental segundo Bardin (2010) como procedimento de análise de dados. Os resultados decorrentes da análise do referencial teórico de Hernández (1998) apontam que os projetos de trabalho contribuem para reflexão e reorganização das práticas pedagógicas na pré-escola e indicam possibilidades de superar a tendência escolarizante que ocorre nesta etapa educativa, favorecendo a construção de práticas que considerem as crianças protagonistas de seu processo educativo.

Palavras chave: Práticas Pedagógicas, Pré-escola, Projetos de Trabalho.

\begin{abstract}
The present article is characterized as a cut of the master's research that is underway in the Graduate Program in Education-PPGE of the Faculty of Sciences and Technology -FCT- Unesp de Presidente Prudente. The objective of the research is to identify and reflect the contributions of the work projects according to Hernández (1998) for the pedagogical practice of the preschool teacher. In order to reach the proposed objectives, the research was based on the principles of qualitative research, and Bardin (2010) used document analysis as a data analysis procedure. The results of the analysis of the theoretical reference of Hernández (1998) indicate that the work projects contribute to the reflection and reorganization of the pedagogical practices in the preschool and indicate the possibilities of overcoming the educational tendency that occurs in this educational stage, favoring the construction of practices That consider the children protagonists of their educational process.
\end{abstract}

Keywords: Pedagogical Practices, Preschool, Work Projects. 


\section{INTRODUÇÃO}

Este artigo se constitui como um recorte da pesquisa ${ }^{1}$ de mestrado que se encontra em andamento no Programa de Pós Graduação em Educação-PPGE da Faculdade de Ciências e Tecnologia -FCT- Unesp de Presidente Prudente. O objetivo da pesquisa se caracterizou em identificar as contribuições no referencial teórico do professor Fernando Hernández (1998), capazes de nortear as práticas pedagógicas do professor de pré-escola, de modo a contribuir para a superação das práticas escolarizantes nesta etapa educativa.

A pré-escola se originou no Brasil, com o objetivo de suprir as carências sociais que as crianças pobres apresentavam para o poder público às crianças das classes dominadas eram tidas como "carentes culturalmente" e para remedia-las era necessário uma educação de cunho compensatório.

Kramer (2006, p.24) afirma: “A fim de suprir as deficiências de saúde e nutrição, as escolares, ou as do meio sociocultural em que vivem as crianças são propostos diversos programas de educação pré-escolar de cunho compensatório".

Deste modo a pré-escola passa a ser encarada para superar as dificuldades que as crianças apresentavam no ensino primário grau, desenvolvendo uma educação compensatória, culpabilizando-as pelas causas do seu fracasso e reforçando mais ainda a discriminação social já existente.

Num processo longo permeado por lutas de diversos movimentos sociais, as políticas de atendimento a criança pequena foram se modificando, com a inserção da Educação Infantil como uma etapa da educação a Constituição Federal de 1988 ao determinar em art. 208: "O dever do Estado será efetivado mediante a garantia de; inc.IV- educação infantil, em creche e pré-escola, á criança de até 6 (seis) anos de idade." A Constituição Federal impõe uma obrigatoriedade ao Estado, no sentido de garantir a educação de crianças pequenas.

Posteriormente no ano de 1996 a Lei de Diretrizes e Bases da Educação Nacional, lei número 9394/96 afirma em seu art. 29.

A educação infantil, primeira etapa da educação básica, tem como finalidade o desenvolvimento integral da criança até seis anos de idade, em seus aspectos físicos, psicológico, intelectual e social, completando a ação da família e da comunidade. (BRASIL, 1996).

A partir desse momento são intensificadas as discussões em torno do atendimento a criança pequena, e são construídas em razão de diversos estudos e debates vários documentos para subsidiar o trabalho do professor de Educação Infantil, destacamos dentre eles as Diretrizes Curriculares Nacionais para a Educação Infantil-2009 documento mandatório para a construção de práticas educativas que respeitem a infância.

A criança, centro do planejamento curricular, é sujeito histórico e de direitos que se desenvolve nas interações, relações e práticas cotidianas a ela disponibilizadas e por elas estabelecidas com adultos e crianças de diferentes idades nos grupos e contextos culturais nos quais se insere. (BRASIL, 2009, p.6).

Com isso, para esta investigação nos pautamos numa concepção de criança protagonista do seu desenvolvimento, e nesse sentido buscamos nos projetos de trabalho segundo Hernández (1998) contribuições que norteiem a prática pedagógica do professor de préescola.

De acordo com Hernández (1998) os projetos de trabalho fazem parte de uma concepção de educativa favorecedora da pesquisa e da construção do conhecimento de forma

\footnotetext{
${ }^{1} \mathrm{O}$ título da pesquisa não foi informado, pois se encontra em processo de reformulação.
} 
compartilhada, com o intuito de ampliar o repertório das crianças num contexto de experiências de aprendizagem significativas.

\section{METODOLOGIA}

Para a construção desta investigação nos apoiamos na abordagem qualitativa, Segundo Chizzotti (1995, p. 79) "há uma relação dinâmica entre o mundo real e o sujeito, uma interdependência viva entre o sujeito e o objeto, um vínculo indissociável entre o mundo objetivo e a subjetividade do sujeito". Isso implica uma relação continua entre o objeto de estudo e o pesquisador.

A investigação tem como corpus de análise o referencial teórico publicado pelo professor Fernando Hernández (1998), onde procuramos compreender as contribuições dos projetos de trabalho no que se refere à organização da prática pedagógica do professor e suas possibilidades na superação de práticas escolarizantes na pré-escola.

Este estudo se caracteriza como bibliográfico que tem como fonte de dados documentos de cunho científico.

A pesquisa bibliográfica é feita a partir do levantamento de referências teóricas já analisadas, e publicadas por meios escritos e eletrônicos, como livros, artigos científicos, páginas de web sites. Qualquer trabalho científico inicia-se com uma pesquisa bibliográfica, que permite ao pesquisador conhecer o que já se estudou sobre o assunto. Existem, porém pesquisas científicas que se baseiam unicamente na pesquisa bibliográfica, procurando referências teóricas publicadas com o objetivo de recolher informações ou conhecimentos prévios sobre o problema a respeito do qual se procura a resposta (FONSECA, 2002, p.32).

Com esse entendimento, para alcançarmos os objetivos propostos e refletirmos sobre os estudos de Hernández (1998), lançamos mão da análise documental. De acordo com Bardin (2010, p. 51), a análise documental pode ser definida como "[...] uma operação ou conjunto de operações visando representar o conteúdo de um documento sob uma forma diferente da original, a fim de facilitar, num estado ulterior a sua consulta e referenciação". Por meio da análise documental buscamos interpretar o conteúdo da mensagem de modo a encontrar respostas para o problema que motivou a pesquisa.

\section{RESULTADOS}

A análise do referencial teórico do autor Hernández (1998) nos permitiu inferir que os projetos de trabalho são uma possibilidade de organização do conhecimento que privilegia o desenvolvimento da curiosidade, estimulando a construção de diferentes pontos de vistas sobre determinado assunto. Compreendemos que os projetos de trabalho se sobressaem às práticas disciplinadoras e repetitivas em que são pautadas as atividades na Educação Infantil, especificamente na pré-escola.

Nos projetos de trabalho, as crianças são consideradas coautoras de um percurso de aprendizagem que é permeado por diversas relações, diferentes linguagens e formas de abordar o conhecimento. Todos esses aspectos são planejados de forma flexível e de acordo com as necessidades do grupo. Barbosa e Horn (2008, p. 42) afirmam: "As aprendizagens nos projetos acontecem a partir de situações concretas, das interações construídas em um processo contínuo e dinâmico".

Nessa concepção de aprendizagem, o professor adota uma atitude de escuta e diálogo, planejando materiais e recursos que possibilitem que a criança esteja em contato com diversos 
objetos da cultura, através de diversas relações que vão se delineando com a participação de todos os sujeitos envolvidos no processo de ensino e aprendizagem.

Nos projetos, as crianças aprendem a argumentar sobre suas escolhas, relacionam diferentes tipos de conhecimentos, através da seleção de várias informações. Aprendem também a trabalhar em grupo, ouvir o outro e compreender que o conhecimento se constrói a partir da conexão de diferentes aspectos e, com isso, são estimuladas a dar explicações coerentes aos fatos e conceitos, compreendendo diferentes perspectivas do conhecimento.

Diante de um Projeto trabalhado, o realmente importante não é o que a professora faz, e sim o processo de tomada de decisões que realiza quando escolhe alguns materiais e não outros, quando espera um resultado frente a outro possível, quando se propõe alguns objetivos entre uma multiplicidade. (HERNÁNDEZ; VENTURA, 1998, p. 106).

Nesse contexto, os projetos de trabalho atuam como uma forma de organizar o conhecimento que considera a criança como participante das relações sociais e não como um material a ser moldado. Desta forma, a criança vai ampliando seu conhecimento de mundo e se constituindo como um sujeito do conhecimento, por meio de um processo que não é linear e nem cumulativo de informações, tornando a aprendizagem parte do ser e estar no mundo da criança.

A pré-escola torna-se mais um espaço de descoberta sobre a vida. Espaço privilegiado, pois ali se reúnem crianças diversas, com informações, realidades e curiosidades diferentes, que interagem entre si e com a professora, que também traz suas experiências e conhecimentos acumulados. Juntos, constroem novos conhecimentos e se apropriam dos conhecimentos disponíveis, que se revelam pertinentes para o grupo de crianças. (ESTEBAN, 2005, p. 34).

Com isso, a pré-escola se torna um local de descobrimento do mundo, por meio das experiências das crianças para então transforma-las, privilegiando a curiosidade, a indagação, o conhecimento de diferentes pontos de vistas, para compreender as informações que estão em nosso entorno e participar de modo consciente da própria construção de sua aprendizagem.

\section{DISCUSSÃO}

Consideramos os projetos de trabalho como uma possibilidade de repensar a visão escolar das experiências efetivadas na Educação Infantil e principalmente na pré-escola, onde ainda se faz presente a ênfase na preparação das crianças para o Ensino Fundamental.

Diante das discussões tecidas neste percurso de investigação, reconhecemos que os projetos de trabalho colaboram na organização do trabalho pedagógico do professor pré-escolar. Isso pode ocorrer particularmente com práticas pedagógicas que inserem a criança no centro do processo educativo, com intenção de ultrapassar a função disciplinadora e escolarizante exercida pela pré-escola, no momento atual que relação com seu processo histórico de construção

\section{CONCLUSÃO}

Por fim, reiteramos que os projetos de trabalho são uma alternativa para repensar a função da pré-escola como uma instituição de Educação Infantil que tem como princípio favorecer o desenvolvimento das crianças de maneira criativa, respeitando suas particularidades e propiciando atividades que ampliem ao máximo suas capacidades cognitivas, afetivas, sociais e motoras. Nesse sentido, através dessa perspectiva de trabalho, o docente consegue respeitar cada forma singular da criança de se inserir no mundo, ajudando que elas desenvolvam habilidades cada vez mais complexas. 
Com isso, os projetos de trabalho podem levar a pré-escola a qualificar as experiências oferecidas às crianças e reorganizar a forma disciplinadora e mecânica em que são pautadas suas práticas. Podem favorecer a construção de uma aprendizagem colaborativa que alarga o conhecimento já existente, recuperando com isso a função política da pré-escola frente ao conhecimento. Podem, ainda, incentivar as crianças a observarem e questionarem as informações que circulam em seio meio com criticidade, comprendendo-as como produtoras de conhecimentos e culturas, sujeitos capazes de intervir no mundo em que vivem, não apenas reproduzindo informações.

\section{REFERÊNCIAS}

BRASIL, Senado Federal. Constituição da República Federativa do Brasil. Brasília, Imprensa Oficial, Brasília: 1998.

Lei de Diretrizes e Bases da Educação Nacional. Lei n. 9394 promulgada em 20 de dezembro de 1996. Brasília: MEC/SEF, 1996.

. Diretrizes Curriculares Nacionais para a Educação Infantil. Parecer CNE/CEB no 20/2009. Brasília: MEC/SEF, 2009.

BARBOSA, M. C. S.; HORN, M. G. S. Projetos Pedagógicos na Educação Infantil. Porto Alegre: Artmed, 2008.

BARDIN, L. Análise de Conteúdo. Tradução de Luís Antero Reto e Augusto Pinheiro. Lisboa: Edições 70, 2010.

CHIZZOTTI, A. Projeto de pesquisa em ciências humanas e sociais. 2. ed. São Paulo: Cortez, 1995.

ESTEBAN, M. T. Jogos de encaixe: educar ou formatar desde a pré-escola. In: GARCIA, R. L. et al. (Org.). Revisitando a pré-escola. 6. ed. São Paulo: Cortez, 2005.

FONSECA, J. J. S. Metodologia da Pesquisa Científica. Universidade Estadual do Ceará. 2002. HERNÁNDEZ, F. Transgressão e mudança na educação: os projetos de trabalho. Tradução de Jussara Haubert Rodrigues. Porto Alegre: Artmed, 1998.

; VENTURA, M. A organização do currículo por projetos de trabalho: o conhecimento é um caleidoscópio. Tradução de Jussara Haubert Rodrigues. Porto Alegre: Artmed, 1998.

KRAMER, Sônia. A política do pré-escolar no Brasil: A arte do disfarce. 8. ed. São Paulo: Cortez, 2006. 